\title{
Para que Serve o Conceito de Honra, ainda hoje?
}

Fabíola Rohden

IMS/UERJ
Peristiany, J. G. (org.). 1971 [1965]. Honra e Vergonha: valores das sociedades mediterrâneas. Lisboa: Fundação Calouste Gulbenkian.

Peristiany, J. G. \& J. Pitt-Rivers (eds.). 1992. Honor and Grace in Anthropology. Cambridge: Cambridge University Press.

O conceito de honra - ou os núcleos simbólicos comumente a ele associados - pode ser reconhecido como um dos conceitos clássicos da teoria social, básico para a compreensão de determinados sistemas sociais e, muito freqüentemente, tomado mais como um pressuposto que como objeto de estudos. Este ensaio procura contribuir no sentido de fornecer um guia crítico de referências básicas que permita aos leitores vislumbrar as potencialidades e conexões analíticas possíveis por meio da consideração das problemáticas associadas à honra. Percorrendo a bibliografia sobre o conceito é possível perceber que os estudos que têm tratado do tema mantêm-se girando em torno de um conjunto de referências comuns, centradas nas pesquisas que envolveram a chamada "área cultural mediterrânea" e as suas críticas. ${ }^{1}$

Dada exatamente a intensidade das ressalvas feitas às análises envolvendo honra, poder-se-ia perguntar a respeito da validade da sua discussão ainda hoje. 0 que se poderia argumentar, entre outras coisas, é que os estudos agrupados em torno da noção de honra chamam a atenção, particularmente, para as variadas formas pelas quais são encenados ou construídos os conjuntos de valores associados ao gênero e, em particular, aos modelos de família adotados em cada contexto. Esses valores expressam algo importante da sociedade em questão ao mesmo tempo em que funcionam como operadores eficazes de determinados mecanismos sociais. $A$ literatura sobre honra/vergonha mostra as diversas possibilidades concretas como 
Esse núcleo de referências teóricas só se torna desinteressante se desconsiderarmos os intensos e produtivos debates que o conceito de honra provocou dentro da antropologia. O questionamento da idéia de uma "área cultural mediterrânea", da homogeneização que poderia implicar, ou da naturalização de certos "traços" culturais, psicológicos ou comportamentais, promoveu uma rica discussão, expressa exemplarmente nos trabalhos de $\mathrm{J}$. Davis (1977), M. Herzfeld (1980, 1984) e J. de Pina Cabral (1991).

Davis (1977) constrói uma posição em que, ao mesmo tempo em que problematiza a "homogeneidade cultural" do Mediterrâneo, defende a especificidade dos estudos nessa área que se teria singularizado por meio do contato cultural ocorrido historicamente. Já Herzfeld $(1980,1984)$ e Pina Cabral $(1991)$ assumem uma posição mais crítica e focam suas ponderações nos apriorismos conceituais e nas macro-comparações empreendidas por muitos autores. Na verdade, o ponto central, que aparece com mais ênfase no trabalho de Pina Cabral (1991), é que as estratégias de constituição de uma área específica de estudos dentro da antropologia, em torno do Mediterrâneo e da noção de honra, acabaram reforçando os aspectos comuns de culturas muito distintas internamente. As análises terminaram girando em círculos destinados a reificar uma determinada visão etnocêntrica. Além disso, Herzfeld (1980) chama a atenção para as limitações das traduções para a língua inglesa dos variados termos associados à noção de honra nas diferentes culturas do contexto geográfico estudado. Trata ainda do perigoso procedimento envolvido nas generalizações feitas a partir de características culturais de regiões particulares, que acabam reforçando estereótipos como a própria idéia de "mediterrâneo" (Herzfeld 1984).

É interessante notar que tanto Herzfeld (1980) quanto Pina Cabral (1991) fazem uma distinção importante entre os autores que estrategicamente se apegaram à noção de "área cultural mediterrânea" e os trabalhos pioneiros dedicados ao estudo dos fenômenos associados ao tema da honra. Herzfeld (1980:339) afirma que na primeira coleção sistemática de ensaios sobre o tema publicada em 1965 por Peristiany as correlações fáceis eram evitadas por meio de uma "atenção escrupulosa" aos detalhes etnográficos, assim como a comparação transcultural era desejada mas não forçada. No mesmo sentido, Pinal Cabral (1991:89) diz que, apesar dos possíveis erros e defeitos que se possa reconhecer no trabalho dos pioneiros como Pitt-Rivers, Campbell, Stirling ou Friedl, "generalizações, claramente etnocêntricas e indevidamente substanciadas" - comuns nos trabalhos posteriores - não serão neles encontradas.

Temos assim, portanto, ao lado do intenso debate, recuperada a importância dos trabalhos que pretenderam dar conta, de forma inovadora na época, dos sistemas morais associados, aproximadamente, com a noção de honra, em diferentes sociedades. Aproximadamente porque, como será possível perceber nos artigos produzidos ainda na década de 1960, a variação dos termos, do conteúdo acionado e das práticas efetivadas em cada contexto com relação àquilo que apenas analiticamente ou provisoriamente poderia se chamar de "honra" é bastante significativa. De um modo geral, vê-se operando nesses trabalhos o privilégio à etnografia e às análises comparativas mas sem o reducionismo das generalizações mais abrangentes que se tornariam comuns mais tarde.

Além desses aspectos que justificam um interesse no debate teórico a respeito da noção de honra, é preciso enfatizar também um outro fator. Trata-se do fato de que é freqüente uma certa confusão no uso das referências 
à honra nos estudos sobre o Brasil. É claro que não estou me referindo aos estudiosos do tema mas a um certo senso comum letrado que percebe como única ou cristalizada a noção de honra que aparece, por exemplo, em pensadores clássicos da formação nacional e nos discursos cotidianos hoje em dia. ${ }^{2}$ Certamente, temas como honra, vergonha e família têm estado muito impregnados no nosso vocabulário básico de compreensão da sociedade brasileira, mas é preciso ter cuidado com os sentidos atribuídos em cada contexto. A reificação de uma determinada visão única e invariável de honra pode ser muito contraproducente. Seu perigo reside exatamente na força que o termo possui ao ser capaz de associar muitos núcleos simbólicos ou remeter a muitos domínios importantes como gênero, família, política, religião. Sem uma definição clara e precisa, em cada situação etnográfica, honra pode se transformar em um conceito mágico que fecha as explicações sem levar a uma compreensão mais aprofundada dos fenômenos. É exatamente por isso que se faz necessário um conhecimento mais abrangente da história do conceito e dos debates em torno dele. Se usado a partir de um pondo de vista crítico, apoiado no valor dos dados etnográficos, pode ser um recurso analítico interessante.

O conceito de honra aparece na antropologia de forma mais realçada com as pesquisas inaugurais de J. G. Peristiany e J. Pitt-Rivers durante a década de 1960. Seus trabalhos e os de autores próximos chamam a atenção para a importância desse conceito em termos de seu potencial heurístico especialmente em se tratando das sociedades mediterrâneas. A importante coletânea editada por J. G. Peristiany em 1965 - Honra e Vergonha: valores das sociedades mediterrâneas - delimita o entendimento do que seriam os seus princípios básicos e o tipo de aplicação possível em distintos contextos etnográficos. $\mathrm{Na}$ "Introdução", Peristiany explica que o par honra/vergonha faz parte do sistema de regras de conduta ou de regulamentos sociais comum a todas as sociedades. Honra e vergonha seriam dois pólos da valorização social que implica a hierarquização dos indivíduos. São universais, todas as sociedades teriam suas formas de honra e vergonha. Contudo, o autor deixa claro o fato de que algumas sociedades se referem a esta forma de valorização mais constantemente que outras, com destaque para as sociedades da "área cultural mediterrânea" que apresentariam certas continuidades ou persistências na forma de pensar, especialmente quando se considera a relação homem-mulher e os diferentes papéis atribuídos aos sexos.

Mais de quatro décadas depois percebe-se que a produção sobre este tema ainda se mantém atrelada a estes primeiros estudos, mesmo que de uma perspectiva crítica. Uma contribuição de vulto nos últimos anos, pelo menos em termos da junção da vários artigos e autores, é apresentada como um segundo volume do livro de 1965. Trata-se de Honor and Grace in Anthropology, editado por Peristiany e Pitt-Rivers em 1992. Nesta obra evidentemente alguns novos autores aparecem, mas ao lado dos que figuraram na primeira. Há tentativas de redefinições e precisões conceituais e também de respostas às críticas anteriormente suscitadas. Uma análise de sua introdução é bastante reveladora. Os autores sinalizam algumas mudanças na antropologia, como uma maior preocupação com o simbolismo e a religião e afirmam que as discussões sobre honra têm que açambarcar o 
domínio do sagrado, do ritual, do religioso. Aproximações aparecem no sentido de que honra e religião conferem prestígio, a honra é considerado sagrada, honra e graça, desonra e desgraça podem ser equivalentes em alguns contextos. Isto justificaria o título e o objetivo do livro.

Além disso, apresentam o conceito de honra de uma forma bem mais flexível, atentando para os contextos sociais e temporais em jogo e para as manipulações performadas pelos grupos sociais ${ }^{3}$. Honra estaria implicada em diversos aspectos e instituições do mundo mediterrâneo. Representaria não só uma variedade de personalidades sociais presentes em uma dada sociedade, mas também os interesses variados e conflitantes de grupos rivais, como linhagens, clãs, classes ou corporações, que dão precedência, na sua definição de honra, a aspectos que favoreçam sua promoção social (Peristiany e Pitt-Rivers 1992:4). Nesta definição dois pontos são importantes e inovadores. O primeiro diz respeito à dimensão mais abrangente que o conceito ganha na dinâmica social. Os autores dizem que é um erro olhar a honra como um conceito único e constante. Ao contrário, deve estar em foco a noção de um campo conceitual, no qual as pessoas encontram meios para expressar sua estima por si mesmas ou pelos outros. Estaria suposta uma concepção de cultura não como um conjunto de regras de conduta que garantem a organização da sociedade, mas como uma estrutura de premissas conflitantes a partir das quais a luta por domínio tem lugar - o que leva ao segundo ponto. A honra deixa de ser conceituada só em termos de demonstração de precedência ou poder e passa a ser considerado o fato de que o controle de sua definição é também um meio de obtê-la e mantê-la. Exemplos disso são a disputa entre a Igreja e a nobreza sobre a sua definição em termos de dádiva divina ou conquista pelo uso corajoso das armas, ou as distinções entre os tradicionais detentores de posição social e os novos ricos. Cada classe ou grupo instituiria sua própria honra e avaliar-se-ia e aos outros nestes termos.

Peristiany e Pitt-Rivers (1992) trazem ainda o componente paradoxal do conceito de honra, na medida em que esta representa tanto uma questão de consciência moral e um sentimento quanto um fato de reputação ou precedência (ligada à virtude do nascimento, poder, riqueza, santidade, prestígio etc.). Isto implicaria que a honra não pode ser reduzida ou tratada como um epifenômeno de algum outro fato mas que ela obedece a uma lógica própria, o que poderia dissipar este paradoxo. Os críticos do primeiro livro teriam afirmado que honra se referia apenas à distribuição de poder e riqueza, apoiando-se em argumentos reducionistas materialistas e não dando conta do paradoxo evidenciado. Este novo volume, mais uma vez através de exemplos etnográficos, tentaria mostrar como o sistema opera eficazmente.

Uma certa tensão ao aproximar as duas edições ou evidenciar suas diferenças fica patente. Os autores dizem que agora não estão apenas preocupados com o Mediterrâneo mas, em continuação ao livro de 1965, estão centrados na mesma parte do mundo e preocupados com o mesmo tema. Na verdade, o que está em jogo aqui é esclarecer os desentendimentos sobre a noção de Mediterrâneo como área cultural. Argumentam que usaram esta idéia apenas epistemologicamente, não compactuando com estudos que maximizam este conceito e pressupõem uma definição geográfica. Problematizam a precisão com que se pode falar do que está dentro ou fora de uma área cultural. Afirmam que estavam interessados tanto nas semelhanças quanto nas diferenças culturais dos povos que 
circundam o Mediterrâneo. E definem que o "conceito de honra mediterrânea" indica apenas uma tendência em associar honra masculina com pureza sexual feminina, pois há áreas no Mediterrâneo onde ela não ocorre ou a variação é muito grande.

Outro mal-entendido que tentam esclarecer é que, quando usaram o termo shame no título do primeiro livro, não pretendiam entrar na distinção da cultura mediterrânea como shame culture ou guilt culture no sentido usado por M. Mead. Dizem que até poderiam ter usado o termo infamy, mas que não o fizeram porque infâmia se restringe à conotação de reputação, não enfocando também os sentimentos, o que transparece em vergonha.

Depois de esclarecidas essas pendências, pode-se passar para uma análise mais geral dos usos do conceito de honra e discutir alguns pressupostos teóricos implícitos nas análises concretas.

III

Inicialmente vou examinar os artigos produzidos na década de 1960, tentando articular suas principais proposições, para depois estabelecer algumas relações com os trabalhos mais recentes.

Os textos de J. Pitt-Rivers são os que mais acuradamente têm procurado definir o conceito de honra. ${ }^{4}$ Honra aparece como possuindo uma estrutura geral presente nas instituições e valores de uma determinada cultura. Seus princípios estariam em toda parte, mas seu significado variaria no tempo, no espaço e de uma classe para outra. Validar-se-ia a si mesmo a partir da interpretação que fornece aos fatos, envolvendo-se em contradições que refletem os conflitos da própria estrutura social (Pitt-Rivers 1979). Além disso, honra poderia ser entendida como um nexo entre os ideais da sociedade e a sua reprodução no indivíduo (Pitt-Rivers 1971), o que abre dois leques de apreciação: a) honra como atributo individual; e b) honra com relação às solidariedades sociais.

\section{a) Honra como atributo individual}

Honra neste sentido é o valor que uma pessoa tem aos seus olhos e aos olhos da sociedade, por meio da conformação a determinadas formas de conduta. É uma reclamação pessoal de orgulho e também a aceitação do direito ao orgulho. Sentimentos, condutas, reputação e concessão de honra estariam implicados. Nas sociedades complexas, tende a haver uma fissura entre os pólos do sentimento e modo de conduta e da honra como benefício outorgado (por um monarca, por exemplo). Esses diferentes critérios entram em jogo em distintos momentos históricos e de acordo com o tipo de hierarquia que se estabelece em cada sociedade.

Outro ponto importante é a relação entre honra e pessoa física: a importância da cabeça como locus preferencial de reverência ou afronta à honra, a referência ao sangue etc. Há também a questão da intenção. O que importa são os sentimentos evocados mais do que o resultado da ação. Nesse caso, a desculpa é uma negação da intenção de ofender, assim como o desafio é sinal da intenção de ofender. Desse modo, se a honra se estabelece ou se impugna através do comportamento físico, isso só é possível porque estão implícitas determinadas intenções. Por um lado, as ações falam mais claramente do que as palavras. Por outro, a forma como se diz é mais importante 
do que as próprias coisas. O conhecimento público também é fundamental. O dano causado à reputação está relacionado com o alcance da opinião pública dentro da qual se difundiu. Esta é o tribunal da reputação. Qualquer ação dependerá de sua interpretação para ser considerada uma afronta ou desafio.

Quanto à guarda da honra, todo homem é responsável e árbitro das situações. Apenas os considerados incapazes (mulheres, doentes, idosos, padres) têm direito a defensores. Aos outros, recusar-se a enfrentar pessoalmente uma ofensa pode também produzir desonra. A violência é, muitas vezes, o recurso característico. Sua execução é obrigatória quando todos os outros meios de resolver as disputas foram ineficientes. Neste caso, recorrer à justiça oficial, ao Estado, significa admitir a sua incompetência ou vulnerabilidade em termos de honra. Um último ponto diz respeito à igualdade entre os atores envolvidos: um homem é responsável pela sua honra apenas diante daqueles com quem compete conceitualmente. Só se sente ofendido e precisa responder aos insultos de quem considera um igual em honra. Responder às injúrias dos outros pode colocá-lo em uma armadilha de desonra (Pitt-Rivers 1979).

\section{b) Honra com relação às solidariedades sociais}

Os grupos sociais possuem uma honra coletiva relacionada à honra de cada membro. A conduta desonrosa de alguém se reflete na honra de todos, ao mesmo tempo em que cada indivíduo participa da honra de todo o grupo. Desde a família até a nação, nos mais diversos grupos, uma pessoa é investida da honra de todo o grupo. Em se tratando de honra coletiva, as intenções ficam subsumidas aos fatos: o indivíduo já nasce filho ou súdito de alguém. Aqui os rituais têm o papel de estabelecer o consenso da sociedade com relação à ordem de prioridade, entre aquele a quem se deve respeito e os que devem respeitar. Nesse sentido, as transações de honra servem tanto para criar uma ligação entre os ideais sociais e a sua reprodução no comportamento individual (a honra estabelecida socialmente dita os critérios sobre o que o indivíduo deve sentir), quanto para relacionar ordem ideal e ordem real, validando as realidades do poder e fazendo com que a ordem hierárquica consagrada corresponda a elas (a honra sentida pelo indivíduo deve ser igual às honras ditadas ou oferecidas pela sociedade). É graças a essa dualidade de significados da honra que um "dever ser" é derivado de um "é", garantindo a legitimação do poder estabelecido e auxiliando na interpretação social (Pitt-Rivers 1979).

Na sua análise sobre a Andaluzia, Pitt-Rivers (1971) dá cor a esses princípios e mostra como são atualizados em uma realidade concreta, além de traçar os marcos do que seria a especificidade da honra mediterrânea. $O$ eixo fundamental é o tratamento da honra sempre associada com o seu par, a vergonha, e a possível intercambialidade entre os dois termos. Vergonha pode ser entendida, de modo semelhante à honra, como a preocupação com a reputação ou o que faz uma pessoa sensível à pressão exercida pela opinião pública. A falta de vergonha é que se equipararia à desonra. Já em um outro plano honra e vergonha seriam distintas e associadas diferentemente aos dois sexos. Uma conduta oposta seria exigida do comportamento de homens e mulheres e haveria uma associação mais forte do homem com a honra e da mulher com a vergonha. Para o homem, o mais importante seria 
a preocupação com a precedência e a propensão para as relações exteriores, como a ofensa e o desafio. À mulher caberia a pureza da conduta sexual, associada à vergonha. Pela complementaridade entre os dois pólos, o centro da honra da família, do grupo, estaria no comportamento das mulheres, mas caberia aos homens a responsabilidade por defendê-la em ofensas públicas. A vergonha, herda-se da mãe. A honra ou direito à precedência, herda-se do pai. A primeira tenta-se manter, a segunda obriga à ação no mundo social. ${ }^{5}$

Além disso, outra consideração fundamental do autor para a Andaluzia se refere à distinção de igualdade $\mathrm{e}$ hierarquia encarnada no sistema de patronagem. Neste caso, a honra é percebida como a tentativa de estabelecer supremacia sobre o outro através do desafio ou outras formas semelhantes. A obediência a alguém não é entendida como humilhante mas pensada em termos de uma lógica da reciprocidade. Serviço e proteção fazem parte dessa lógica: o protetor ou patrono aumenta o seu prestígio ao aumentar o número de seus clientes e estes participam da glória do protetor. Um sistema que é reforçado pelo parentesco ritual através dos laços de compadrio. Além disso, entra em cena a possibilidade de disputas entre os demais servidores, que lutam para atrair os favores dos poderosos, atestando seu potencial de mais ou menos honra (Pitt-Rivers 1979).

O trabalho de J. G. Peristiany (1971) compartilha os principais argumentos colocados por Pitt-Rivers (1971 e 1979). Salienta, por exemplo, que honra e vergonha são dois aspectos de uma mesma regra de valorização social que define os ideais aceitos em cada grupo. Reforça a importância do pudor sexual feminino, embora também enfoque a valorização da maternidade na definição da honra do grupo. Ao estudar uma aldeia cipriota de montanha, o autor demonstra o funcionamento desse sistema de valores seja em relação aos laços estabelecidos com personagens de fora da comunidade, como os "ocidentais" ou indivíduos provenientes da cidade (nos quais nunca se poderia confiar plenamente), seja com referência aos códigos estabelecidos dentro dos grupos menores. Neste último caso mais especificamente, a honra segue critérios de variação de acordo com idade, sexo e posição social e é o que mantém os laços de solidariedade do grupo em ativação. Assim, aqueles que não a possuem ou não a buscam são considerados uma ameaça para a comunidade, pois quando perdem o respeito por si próprios e ignoram o valor social que os outros Ihes atribuem, colocam-se fora da ordem social estabelecida. A pressão do grupo é para que todos se convertam em participantes nas disputas comuns pela honra, consolidando a unidade em questão. Até mesmo os estranhos passam por um processo de tentativa de pessoalização para que possam fazer parte do jogo, já que a honra só entra em operação entre "pessoas" e não entre indivíduos anônimos.

J. K. Campbell (1971) também trabalha com pastores gregos dentro de uma mesma linha de análise. Descreve como o sistema honra/vergonha está embutido na definição de três tipos de laços sociais daquele grupo: a) os parentes pelo sangue - a quem se deve amor e confiança; b) os parentes por afinidade - com os quais se estabelecem as relações de matrimônio, as trocas de honra, mas não a confiança e; c) os estranhos - que ocupam o lugar de quase inimigos e a quem é legítimo tentar explorar. Entre a família e a comunidade interpõem-se relações de hostilidade e desconfiança, a possibilidade de macular a reputação, a necessidade de segredo, a possibilidade do roubo e de incidentes de violência física. As famílias implicadas competem por distância social, o que depende de sua aceitação e aderência a um sistema de valores comum e da aprovação de seus méritos pelos outros, que 
em geral é dificultada. A base do reconhecimento está na admissão de que todos têm honra, com a qual se nasce (com exceção das famílias de status social muito baixo), mas que se tem a possibilidade de perder. É um estado de integridade que é preciso manter e que relaciona atributos físicos e morais. Comporta tanto o agregado da família quanto a avaliação do comportamento individual, distinguido pelo sexo. Ao homem cabe a força de corpo e espírito, a coragem e a eficácia das ações. ${ }^{6}$ À mulher, a vergonha, o pudor, a repugnância instintiva pela atividade sexual, a necessidade de disfarçar os atributos físicos, a virgindade, de fato nas solteiras e em pensamento nas casadas. Masculinidade e pudor são complementares e juntos formam a possibilidade da honra do grupo. Além desses termos gerais, Campbell se preocupa em identificar o que qualifica como um paradoxo: a honra como uma qualidade egoística e particularística, que enfatiza os interesses individuais e imediatos de cada grupo ou indivíduo, e sua convivência com uma moralidade cristã, calcada na fraternidade e na solidariedade. Recorrendo à figura do diabo, explica que essas duas orientações convivem na medida em que se desloca para aquele toda a fonte de hostilidades e tensões e se privilegia a noção de família sagrada, que justifica todas as disputas para a manutenção de sua integridade e de seus interesses.

De certa forma, essa preocupação com a dimensão do sagrado também é enfocada por P. Bourdieu (1971) no seu estudo sobre honra na sociedade cabília. Ele trabalha com a série de oposições que caracterizam diversos planos de funcionamento dessa sociedade, com destaque para a distinção entre nif, que significaria o ponto de honra, o amor próprio, o respeito, a vontade de superar o outro, e hurma, que seria a honra em sua totalidade, o conjunto do que é interdito, do que é sagrado para o grupo, caracterizando também a sua vulnerabilidade. Enquanto o desafio coloca em xeque o ponto de honra, o nif, o ultraje atinge as regiões interditas e é considerado sacrilégio. Se o julgamento social (novamente o reconhecimento e interpretação públicos são fundamentais) define que a ofensa foi sobre a hurma, o indivíduo deve sentir acionado o seu nif, deve ter a obrigação da vingança, sob pena de perder sua honra e só lhe restar o exílio. O nif é o responsável pela guarda da hurma, estando ambos intimamente conectados: "Assim, a integridade da hurma é função da integridade do nif, estando aquele que não tem nif particularmente exposto a ver a sua hurma atingida pela ofensa e a perdê-la completamente por não ter tido coragem para defendê-la. A honra define-se assim pelo par indissociável formado pelo nif e pela hurma" (1971:176). A concepção do sagrado objetiva-se em oposições espaciais, isolando certos domínios para sacralizálos especialmente a partir do par complementar dentro/fora. O pólo "dentro" faz remissão ao espaço feminino, ao domínio dos sentidos e sentimentos, enquanto que o "fora" indica o espaço masculino, a exterioridade das relações de diálogo e troca estabelecidas entre os homens. Além disso, a distinção entre os sexos comporta também a associação das mulheres com poderes mágicos e com uma sexualidade culpada e vergonhosa, enquanto os homens estariam do lado da religião e da virilidade reforçada em termos de força e prestígio.

O sistema de oposições, do qual citei apenas algumas mais ilustrativas, constitui uma hierarquia de valores que ordena as regras de conduta daquela cultura. Os princípios agrupados em torno da honra compõem um código comum que permite julgar ações próprias e alheias. Em termos gerais, essas proposições de Bourdieu se coadunam com as dos outros autores vistos. Contudo, a riqueza de possibilidades de focar cada situação, os 
diversos e múltiplos ângulos apresentados quando se leva em conta a ação implicada, abrem espaço para uma certa relativização da preeminência do social sobre o indivíduo. A abertura à escolha e a estratégias individuais na manipulação das regras propostas pela sociedade traz uma nova dimensão à consideração da honra como elemento de mediação entre os padrões sociais idealizados e a atualização no comportamento dos indivíduos (ver Bourdieu 1971 e 1972).

O texto de A. Abou-Zeid (1971), de um modo geral, respeita os argumentos estabelecidos pelos outros autores na definição da honra e sua concretização na sociedade. Na sua análise sobre os beduínos do Egito, afirma que honra se refere à adesão aos padrões tradicionais de comportamento, tem como resultado a institucionalização de certas distâncias e superioridades entre os indivíduos, revelando-se um instrumento de controle social que pune, inclusive, as manifestações excessivas de posse de honra que podem colocar laços sociais em perigo. É recorrente também a valorização da castidade e prudência femininas no cálculo da honra do grupo.

Já o artigo de J. C. Baroja (1971) é o que se distancia um pouco mais dos outros, não tanto por divergências teóricas, mas pela especificidade de tratar do fenômeno nas suas manifestações históricas na sociedade ocidental. O autor mostra como a honra neste caso descende de três matrizes culturais: a) o mundo clássico; b) o mundo germânico ou bárbaro; e c) o cristianismo. Explica como na Idade Média prevalece a convicção de que os homens formam uma "comunidade de fiéis", resultado das propagações cristãs, por oposição, por exemplo, a uma "comunidade de cidadãos" que gerenciaria a época clássica. Um dos seus exemplos mais interessantes de como a concepção de honra vai variando historicamente e sendo alvo de disputas segundo a ascensão de determinadas classes se refere às brigas entre nobreza e judeus, uns detentores tradicionais das glórias heróicas, outros dententores do poder econômico. Nesse caso, entra em cena também a simbolização freqüente da honra no sangue, expressa na noção de sangue impuro ou maculado dos não-cristãos ou cristãos-novos.

Na edição portuguesa de Honra e Vergonha acrescentou-se mais uma análise a título de prefácio. Trata-se do artigo de J. Cutileiro (1971), que tenta aplicar as premissas da noção de honra mediterrânea a uma comunidade do Além-Tejo. Apesar de reforçar os principais pressupostos já descritos, chama a atenção para a importância da estratificação social e da distribuição de poder político e econômico na diminuição da valorização da família e na rigidez das atitudes e posições, o que traria certas nuanças ao ideal tradicional de honra.

Passo agora a uma resenha dos artigos publicados na coletânea de 1992, agrupando-os em torno de alguns eixos. Um primeiro seria o dos textos que privilegiam análises históricas (Lafages, Lauderie, Baroja e Campbell). Um segundo se refere ao contexto da sociedade ocidental atual (Bourdieu). Um terceiro diz respeito às atualizações etnográficas do conceito de honra em comunidades do Mediterrâneo (Peristiany, Di Bella, Jamous e Ott). E, por último, a discussão mais teórica de Pitt-Rivers sobre o conceito de graça e suas aproximações com a honra.

C. Lafages (1992), ao analisar os rituais funerários e de coroação na França da Idade Média, mostra como se dá a conjunção entre honra e graça na pessoa do rei. Através dele os poderes temporal e espiritual são combinados 
e transmitidos, além de servirem de sustentação um para o outro. O rei, enquanto símbolo paradigmático, é capaz de comportar conjuntamente os dois planos de legitimação de sua posição superior. Somente ele tem o dom de efetivar a transmissão de um tipo de parentesco mortal e individual e de um outro eterno e institucional. Já E. L. Lauderie (1992) nota algumas mudanças na concepção do poder real se comparado com o tratado acima. Sugere que a sacralidade do rei teria mudado na época de Luís XIV na medida em que o nascimento passa a ter privilégio sobre a coroação, o que levaria a uma maximização do poder sagrado do rei. Ele é sagrado em si mesmo, por sua condição pessoal e não mais pela graça de Deus. Honra e sagrado continuam juntos, mas a origem de sua ligação teria se deslocado. ${ }^{7}$

O artigo de C. Baroja (1992) revela continuidades com o publicado em Honra e Vergonha (1971). Retoma o tema das mudanças dadas historicamente na definição do conceito de honra, que vai permanentemente ganhando novas conotações a partir da classe social que tem o predomínio de sua definição e das ameaças que recebe. Focando na Espanha dos séculos XVI e XVII, o autor mostra como se dão as disputas pela precedência, passando pela glória das armas, tradição ou dinheiro entre três importantes grupos: soldados, aristocracia e mercadores. ${ }^{8}$

Uma análise mais audaciosa é a feita por J. K. Campbell (1992), que traça relações entre os heróis gregos da época clássica e pastores montanheses da Grécia continental durante o século XVIII. Aqui o que entra em ação são valorações em distintas épocas de um modelo de herói que encena as expectativas e as tensões vividas pela sociedade. Esta temática já tinha aparecido de uma forma mais sutil no seu artigo de 1971, onde discorria sobre os padrões arquetípicos femininos, representados na figura abnegada e recatada de Maria, e masculinos, encarnados na castidade e sacrifício de Cristo e no espírito guerreiro e corajoso de São Jorge e São Demétrio. ${ }^{9}$

O artigo de P. Bourdieu (1992) não trata diretamente da questão da honra mas do que poderíamos chamar de uma atualização do processo de conquista de honra ou mesmo graça em alguns rituais contemporâneos. ${ }^{10}$ Trata de alguns ritos de passagem na educação formal dos jovens como exemplos do que chama "atos de instituição" ou "de consagração". Estes seriam eventos que têm a capacidade de colocar em operação elementos de natureza mágica, detentores do poder de diferenciação e, por isso, distribuidores de prestígio e distinção social. ${ }^{11}$

Os ensaios que descrevem a honra em diferentes contextos da área mediterrânea comportam uma unidade maior e mais definida. O artigo de Peristiany (1992) demonstra mais uma aplicação dos códigos sociais em situações específicas através de um personagem particular, o sophron. Este seria um mediador ou um árbitro da honra. A comunidade atribuiria a ele o poder de avaliar e decidir sobre a natureza de conflitos diversos. Ele tanto teria poderes para discernir sobre os atributos da honra individual e adequada à posição do sujeito em termos de sexo e idade, quanto para julgar as disputas que envolvem a comunidade como um todo, colocando em questão a reputação coletiva. Na verdade, sua função fundamental é fazer com que se apliquem aqueles preceitos mais gerais ou ideais que fundamentam a consciência coletiva da comunidade em situações particulares. Sua preocupação deve ser o bem comum, sua perícia se revela na medida em que alcança o fim de ajustar os interesses em conflito e a harmonia do grupo é restabelecida.

M. P. Di Bella (1992) mostra como na Sicília as definições do conceito de honra mediterrânea são vivenciadas na prática, com destaque para alguns aspectos particulares. Traços gerais, como a castidade para as mulheres 
e a coragem para os homens, a generosidade, a proteção e hospitalidade com os estrangeiros, a piedade com os inimigos, a firmeza no julgamento, combinam-se na argumentação em torno de dois termos: sangue e nome. A honra de um grupo depende, nesse caso, da complementaridade ideal entre esses dois pólos, que também estão associados a masculino e feminino: enquanto a pureza de sangue deve ser uma característica essencial do comportamento das mulheres, a fama ou o renome deve ser de responsabilidade dos homens. A honra coletiva depende da preservação do sangue e do nome de qualquer mácula. O papel da mulher é assegurar a continuidade do grupo pela reprodução e salvaguarda de sua genealogia, relacionada diretamente com a observação da castidade. Deve preservar a pureza do sangue que herdou e que vai transmitir aos filhos. Enquanto seu status é baseado mais em símbolos, o status masculino é baseado em atos de bravura e conquista. Quando jovens, os homens devem dar provas de habilidade e coragem para defender o seu ponto de honra e mostrar que são merecedores do nome da família que estão herdando. Já quando velhos, devem mostrar sua capacidade para liderar o grupo familiar com a mesma sagacidade e prestígio de seus pais. A complementaridade entre os papéis masculinos e femininos é especialmente sentida no caso de ameaças à honra do grupo. Em caso de adultério de uma mulher do grupo com alguém de fora, o que caracteriza uma ofensa ao sangue, o homem responsável pelo grupo deve agir para recuperar a honra, até mesmo eliminando a mulher em questão. Já no caso de uma ofensa ao nome, seja verbal ou através de atos contra algum membro do grupo, a vergonha é também sentida pelas mulheres que, com palavras, canções ou ações incentivam, encorajam, ou mesmo impõem aos homens do grupo tomar atitudes restauradoras.

Além disso, a autora chama a atenção para uma função mais fundamental da honra que seria fazer a conexão entre o passado de uma sociedade e o seu futuro (1992:152). Mais claramente, graças a sua pureza genealógica e às proezas de seus antepassados, o grupo adquire um prestígio social que no momento presente garante sua possibilidade de controle sobre a história. Na prática, as pessoas racionalizam seus atos e fabricam uma imagem de suas sociedades que valida as suas próprias pretensões de honra, ou seja, estão empregando estratégias conscientes para dar a elas mesmas um código pelo qual orientam suas decisões de vários tipos. Os grupos constroem sua força econômica e política com base na honra que herdam; por outro lado, a honra se desenvolve de acordo com o maior ou menor progresso econômico e político dos grupos, desenhando um jogo onde passado e presente se combinam centrados na referência do sangue e nome. Di Bellla acrescenta ainda que, em termos ideais, a manutenção da honra implicaria um confinamento do grupo, pois a integridade do sangue e do nome só seriam devidamente garantidas com um detalhado conhecimento e severo controle de seus membros. A prática da endogamia e o casamento preferencial com a filha do irmão do pai seriam explicados nestes termos.

Depois desta descrição dos pontos de referência da honra, a autora segue mostrando como na prática aparecem algumas transformações. É o caso, por exemplo, de um grupo que vê um dos aspectos da honra degradado (o nome) e passa a centrar a sua honra no outro (o sangue, através da valorização da pureza sexual de suas mulheres). No caso etnográfico escolhido, mostra como esses princípios gerais da honra são também atributos da graça. Assim como a honra, a graça se compõe de dois termos, o voto ou promessa e o milagre, e seu ponto 
ideal é alcançado pelo balanceamento entre os dois. Esses termos se personificam no crente que faz o voto e no santo que potencialmente realiza o milagre. Referências como a reputação, o fazer saber-se merecedor de um milagre indicam a proximidade entre graça e honra. Ao mesmo tempo, a graça também tem a qualidade de invocar a relação entre passado e presente da comunidade: tanto um santo milagreiro quanto o fiel recebedor passam a fazer parte da memória coletiva e do arcabouço de prestígio do grupo. A relação entre os dois conceitos ainda chega a um último degrau: obter uma graça pode ser a possibilidade de alguém contrabalançar a sua incapacidade por competir por honra.

O artigo de R. Jamous (1992) trata do conceito de honra e baraka (que estaria mais próximo da graça) em uma comunidade (Iqar'iyen) no Marrocos. Inicia dando uma conotação mais ampla e talvez menos flexível ao conceito de honra, optando pela primazia dos controles sociais sobre o indivíduo. Segue definindo honra como o exercício da autoridade sobre os domínios do proibido (território para os grupos segmentários, terra e mulheres para o chefe de cada grupo doméstico) e a transgressão desses domínios de outros possuidores, por meio de trocas. As trocas efetivam as distinções entre os indivíduos e os grupos. Cada homem que é impelido a elas não pode simplesmente assumir uma conduta defensiva, mas deve atuar agressivamente no campo posto, atacando aqueles que são merecedores, ou seja, os iguais em honra. Todas as trocas empreendidas têm o mesmo fim, que é a morte real ou simbólica, e todos os homens de honra são alternativamente sujeitos e objetos delas. As trocas violentas seriam as mais perigosas e por isso as mais bem reguladas pela sociedade.

Além disso, Jamous (1992) também traça um interessante paralelo entre tipos ideais de honra e aquilo que é possível no nível da comunidade. Cita o herói grego Aquiles, tal como analisado por J. P. Vernant (1991), como personagem que paradigmaticamente singulariza seu destino pessoal a partir de uma conduta gloriosa. Ele vive à margem da sociedade durante sua vida e através de sua morte heróica se inscreve na história da sociedade. ${ }^{12}$ Já o ideal do jovem pastor apresentado por Campbell (1992) indica o corajoso, que não suporta afrontas sem respostas violentas e é abstêmio de relações sexuais, instaurando um tipo de honra ideal que é distinta da honra ordinária pregada pelos pastores. Estes precisam ser mais maleáveis às necessidades cotidianas e concretas. Para a tribo marroquina em questão, as qualidades de juventude e coragem heróica também não são suficientes para definir a honra. Demonstrações excessivas desses atributos podem até prejudicar. O jovem filho deve subordinar suas proezas ao controle e interesses dos pais.

Além disso, no plano local não há uma figura que personifique todos os pólos importantes da honra. Os "grandes homens", líderes de grupos, são importantes e detêm a honra mais terrena ou secular, aquela que instiga às trocas violentas. Por outro lado, a honra de tipo divino, a baraka, só é possuída pelos sharifos, descendentes do Profeta e considerados mediadores divinos. A concretização do sistema exige que os dois tipos de honra entrem em ação: para que a comunidade se mantenha é necessário tanto o exercício da honra terrena que mobiliza a troca, fundamental para o grupo, quanto a introdução da baraka, da paz divina providenciada pelos mediadores. Em um plano fora da comunidade, o sultão poderia ser pensado como o personagem que engloba os dois tipos de honra, terrena e divina, tendo poder tanto sobre a violência quanto sobre a paz. 
S. Ott (1992) trata da honra em uma comunidade do País Basco Francês. Mais precisamente trata de indarra, um termo que expressa tanto força divina quanto força física, poder, autoridade, influência, abundância, energia, eficácia etc. A autora mostra como o significado deste termo é variado e situacional. É uma qualidade que, dependendo do bom uso, pode significar a manutenção da ordem da sociedade. É o caso, por exemplo, da indarra associada ao vigor sexual. A autora relata dois casos distintos. No primeiro, um homem usou sua indarra apropriadamente na geração de seus treze filhos. Sua força procriativa é vista como um bem para a comunidade. Em outro caso, um homem engravidou uma jovem de dezesseis anos e era tido como possuidor de uma indarra excessiva, prejudicial porque fora do controle.

Além dessa função de controle social, outra função associada ao conceito é o de ligação entre céu e terra, ou de combinação entre os níveis físicos e espirituais - nesse sentido, mais próximo do conceito de graça. Essa possibilidade de lidar com esferas semânticas opostas é considerada com cuidado por S. Ott. Sugere que conceitos como indarra, baraka e mana não devem ser entendidos como conceitos de "valor simbólico zero", como alguns autores têm feito, mas pela associação que são capazes de operar entre diferentes domínios de significado.

É exatamente sobre essa qualidade conceitual que o pós-escrito de Pitt-Rivers (1992) se centra, mapeando o conceito de graça na antropologia e pretendendo dar o tom inaugural de uma nova temática, assim como foi feito com a honra em 1965. ${ }^{13}$ Afirma que o conceito de graça ocupa hoje o mesmo lugar de desconhecido que o conceito de honra naquela época, apesar da importância que tem nas tradições cristã, judaica e islâmica. Problematiza como, nos últimos anos, a antropologia tem se preocupado tanto com a noção de reciprocidade e não tem feito referência ao seu termo complementar, a graça. Graça, nesse sentido, é aquilo que ocupa o lugar do extraordinário, do que é dado em excesso, sem a previsão de retribuição embora, em alguma medida, a possibilidade de resposta sempre esteja colocada. Tenta mostrar como a graça está muito presente no cotidiano, até nos favores mais corriqueiros. Um exemplo seria o agradecimento de alguém a um favor, cuja resposta é a locução "de nada", indicativa da não intenção aparente de esperar compensação. Diz que a ambivalência freqüentemente encontrada na análise da honra, como da graça, localiza-se exatamente neste ponto: a dificuldade de entender a relação entre um valor moral ligado a uma lógica de transação econômica.

Pitt-Rivers continua refinando a especificidade de funcionamento dessa lógica. Distingue as relações de reciprocidade entre: a) relações de troca equivalente e b) relações de amizade ou benevolência. Nas primeiras seria preponderante um tipo de reciprocidade contratual, enquanto nas segundas, reciprocidade de coração. Haveria então dois modos distinguíveis de conduta, governados pelos princípios da graça e da lei, que corresponderiam a uma série de oposições: coração/cabeça, sentimento/conhecimento, visão subjetiva/visão objetiva do mundo, misterioso/ racional, sagrado/profano. Mais especificamente a graça estaria inserida em um outro conjunto de pares: graça/cálculo, casualidade/controle do destino, dádiva livre/contrato, agradecimento/contraparte estipulada, comunidade/alteridade, Gemeinschaft/Gesel/schaft, parentesco por amizade/aliança política, cheque aberto/conta auditada.

Com os exemplos etnográficos, Pitt-Rivers ainda precisa alguns outros elementos. Mostra como na Andaluzia a graça é atribuída distintamente a homens e mulheres. As mulheres estariam privilegiadamente associadas ao 
plano da graça. É o caso, por exemplo, das mulheres curandeiras ou sábias, dotadas de um tipo de poder mágico quase inerente aos seus corpos, o poder misterioso da graça. Em contrapartida, os homens que atuam na esfera da cura o fazem pelo uso de técnicas, algo mais próximo da manipulação racional ou instrumental. ${ }^{14}$ As mulheres também teriam graça pela sua relação com Maria e a recorrência ao nome de Maria e a suas graças é explicada por essa invocação. No contexto rural da França, o autor salienta que o sistema de trocas entre os fazendeiros obedece à lógica da graça. Os favores são manifestos em serviços mútuos mais que em troca de serviços. O que estaria imperando seria a solidariedade da comunidade, que envolve o sacrifício dos interesses individuais imediatos em favor do bem coletivo a longo prazo. $O$ bom nome daquele que é capaz de prestar favores é também sua garantia individual em um futuro difícil, embora essa estratégia nunca seja explicitada.

A discussão final que Pitt-Rivers faz é sobre algumas aproximações entre os conceitos de honra, graça, indarra, baraka, mana, hau. Deixa claro que não está pretendendo reduzir todos esses termos a um único significado. Mas indica que eles têm algumas referências em comum como a idéia de uma troca específica, de caráter extraordinário, uma dádiva, algo que beira também o plano do sagrado. Além disso, sua principal qualidade comum seria o fato de representarem conceitos de uma mesma ordem, de um mesmo tipo de importância para as culturas que os produzem.

Procurei traçar o lugar que o conceito de honra tem ocupado no campo da antropologia e o estatuto heurístico que lhe é atribuído. Isto para alguns estudos clássicos da década de 1960 e para textos que trazem mudanças e flexibilizações ao conceito, o que sugere uma capacidade aplicativa de maior abrangência. A apresentação dos princípios estruturantes da noção de honra, como um código social em operação, e suas descrições em contextos específicos nos fornecem algumas indicações mais gerais.

Em primeiro lugar, destaca-se a idéia de que os vários termos que remetem ao sistema moral e que foram agrupados analiticamente em torno da noção de honra se inscrevem no conjunto das reciprocidades mais gerais instituídas pelas culturas. É porque fornecem referências e operacionalizam alguns tipos dessas trocas que adquirem importância fundamental no entendimento das sociedades em questão. Trocas de bens, mulheres, prestígio, lutas violentas, só assumem uma dimensão organizadora da sociedade na medida em que um sistema de valores, que pode ser traduzido em vários termos próximos da idéia de honra, está sendo acionado.

É este sistema, segundo os autores vistos, que também orienta a relação entre indivíduo e sociedade. Trata-se do código ideal de comportamento, das regras sociais padronizadas em permanente atualização pelos membros do grupo. E aqui temos desde modelos que funcionam com a preeminência do social, das regras, exercendo efetivo controle sobre as pessoas, até aqueles que privilegiam a capacidade criativa dos indivíduos em manipular o que Ihes é fornecido em termos ideais, de acordo com suas realidades cotidianas distintas.

Outro elemento importante é o fato de que o conceito de honra não é único e estável. Ou mais precisamente, além dos termos específicos variarem enormemente entre diferentes sociedades, não sendo possível universalizar 
ou generalizar uma única noção de honra, também sofrem variações e redefinições a partir das suas atualizações concretas na interação social. O que as etnografias têm mostrado com bastante clareza é que termos como baraka e indarra expressam variações com relação à noção ocidental de honra - por si só já bastante problemática, se tomada como única e invariável. E, especialmente, distinguem-se porque comportam no seu significado uma aproximação com a idéia de graça, uma referência à dimensão do sagrado. Isso nos leva a um último ponto.

O conceito de honra e seus 'similares' teriam como uma de suas funções colocar em operação a ligação entre passado e presente de uma sociedade. Nos exemplos trazidos pelos autores, há uma constante referência ao ideal dos antepassados do grupo, em termos de pureza, de proximidade com o sagrado e a exigência de um comportamento determinado no presente. Também nesse sentido, expressariam a capacidade mediadora descrita por Pitt-Rivers (1992). De um modo geral, funcionariam como 'operadores' que servem para colocar em contato diferentes dimensões do plano social, como a relação entre cultura e natureza, sagrado e profano, masculino e feminino, passado e presente. Seriam mediadores para as trocas entre grupos e entre indivíduos, além de representarem o que capacitaria ou não alguém a se inscrever em um segmento social. Desse modo, constituiriam a matriz de referências que fornece índices para a composição da hierarquia de valores que rege a vida coletiva, permitindo assim compreender a complexidade da relação entre indivíduo e sociedade.

Fabíola Rohden, mestre e doutora em Antropologia Social pelo Museu Nacional (MN/UFRJ), é professora adjunta do Instituto de Medicina Social 


\section{NOTAS}

1 Não é objetivo deste texto analisar a produção que incide sobre o contexto brasileiro. Mas, é relevante mencionar que vários estudos têm chamado a atenção para a importância dessa categoria nesse cenário, considerando problemáticas específicas e apontando críticas pertinentes ao "modelo mediterrâneo". Ver, por exemplo, Corrêa (1981), Aragão (1983), Duarte (1984), Dória (1994), Fonseca (2000), Caulfield (2000).

2 Sobre honra e família em alguns pensadores da formação nacional, ver Rohden (2000).

3 Nesse sentido, estariam mais próximos das análises de P. Bourdieu (1971, 1972), que privilegiam as estratégias individuais na manipulação das regras impostas pela sociedade, dando uma abertura à consideração da honra como elemento de mediação entre os padrões sociais e sua atualização no comportamento individual.

4 Ver especialmente Honra e Posição Social (1971) e Antropología delHonor (1979).

5 Em outro texto (1977), Pitt-Rivers aprofunda a relação entre honra e gêneros, nos termos de um único padrão que exige comportamentos e valores diferenciados para homens e mulheres. Pesquisas mais recentes têm criticado em particular as conexões estabelecidas por esses textos entre honra/vergonha e gênero masculino e feminino, alegando um certo androcentrismo dos pesquisadores. Ver, por exemplo, Abu-Loghod (1986, 1993).

6 E aqui há uma diferença com Pitt-Rivers (1971 e 1979), que privilegia as intenções e não os resultados.

7 Sobre a noção de honra que se instaura na Europa da Idade Média entre nobres e cavalheiros e pobres e humildes, ver R. Muchembled (1991).

8 Michelle Perrot (1991), escrevendo sobre família, cita a multiplicidade de códigos de honra na França oitocentista.

9 Na linha de trabalho sobre mitos que justificam nossa história, J. P. Vernant (1991) trata da "bela morte de Aquiles". Segundo o autor, mais do que tudo, a narrativa de Aquiles representa a possibilidade de dois tipos de vida completamente diferentes: a do herói, centrada na competição por glória, mas cujo resultado imediato é a morte terrena; e a vida longa, declinante e sem glória dos homens comuns. O mais interessante na análise de Vernant é apontar como a trajetória do herói abre espaço para um tipo de vida singularizante, traço que contribui para a formação do indivíduo moderno.

10 B. Lefèbvre (1991) tenta fazer a passagem entre antigas concepções de honra e suas atualizações, especificamente para o caso das profissões. Ele argumenta como algumas profissões que se organizam através de corporações concebem códigos de honra particulares, como os advogados ou os soldados, por exemplo. Mostra ainda como essa honra profissional se articula com as morais religiosa, estatal e popular. E identifica hoje uma permanência desse modelo de comportamento, apesar da degradação da noção de honra corporativa no século XX.

11 M. F. Lévy, A. Muxel e A. Percheron (1991) estudaram as noções de honra entre 1.300 estudantes franceses de liceus e colégios, em 1990. Das suas principais conclusões, destacam-se a variação que a definição de honra pode alcançar e a localização de três vértices principais de origem: a) a referência ao passado, que em geral é transmitida na escola e em outras instituições, como as histórias heróicas, por exemplo; b) a honra como um atributo social que deve ser compartilhado por todos em sua vivência comum; e c) a honra que diz respeito ao indivíduo, a uma interpretação interiorizada. Diante dessas três referências, notou-se que enquanto o primeiro pólo vai perdendo força (já não se valoriza tanto o heroísmo, a abnegação), o último ganha destaque, indicando uma preeminência de concepções individualistas. A honra é ainda um princípio moral evidente e fundamental. Mas o lugar que ocupa hoje é o do implícito e mascarado, distante das situações heróicas e próximo do cotidiano concreto.

12 Em texto que sugestivamente se chama "De quoi Parlent les Fusils?", R. Jamous (1991) dá pistas para pensar a relação entre conflitos violentos e valores culturais em jogo.

13 No artigo "La Maladie de I'Honneur", Pitt-Rivers (1991) discute a universalidade e a atualidade do conceito de honra. Trafega entre a valorização dos estudos originais que identificaram a honra mediterrânea e a relativização de sua adequação mesmo naquela "área cultural". Fazendo uma avaliação do quadro já no final do século XX e respondendo à pergunta sobre a honra estar obsoleta, sugere que foi expurgada da língua, mas não do sistema simbólico. Neste, permanece efetiva e preponderante. Pode-se observá-la em plena ação no campo político, por exemplo.

14 Pitt-Rivers aproxima essa distinção daquela elaborada por Evans-Pritchard (1978) entre bruxos e feiticeiros: as mulheres seriam bruxas, os homens feiticeiros. 


\section{REFERÊNCIAS BIBLIOGRÁFICAS}

ABOU-ZEID, Ahmed. 1971 [1965]. "Honra e Vergonha entre os Beduínos do Egito". In J.G. Peristiany (org.). Honra e Vergonha: valores das sociedades mediterrâneas. Lisboa: Fundação Calouste Gulbenkian.

ABU-LUGHOD, L. 1986. Veiled Sentiments: honor and poetry in a Bedouin society. Berkeley, Los Angeles: University of California Press.

. 1993. Writing Women's Worlds: Bedouin stories. Berkeley, Los Angeles: University of California Press.

ARAGÃO, Luiz Tarlei de. 1983. “Em Nome da Mãe”. In B. Franchetto et al. Perspectivas Antropológicas da Mulher, vol.3. Rio de Janeiro: Zahar.

BAROJA, Júlio C. 1971 [1965]. “Honra e Vergonha: exame histórico de vários conflitos”. In J.G. Peristiany (org.). Honra e Vergonha: valores das sociedades mediterrâneas. Lisboa: Fundação Calouste Gulbenkian.

1992. "Religion, World Views, Social Classes, and Honor during the Sixteenth and Seventeenth Centuries in Spain. In J. G. Peristiany \& J. Pitt-Rivers (eds.) Honor and Grace in Anthropology. Cambridge: Cambridge University Press.

BILLACOIS, François. 1991. "Flambée Baroque et Braises Classiques”. In M. Gautheron (org.) L'Honneur. Image de soi ou don de soi: un idéal équivoque. Paris: Autrement. Série Morales № 3.

BOURDIEU, Pierre. 1972. Le Sens Pratique. Paris: Minuit.

1971 [1965]. “O Sentimento da Honra na Sociedade Cabília”. In J.G. Peristiany (org.). Honra e Vergonha: valores das sociedades mediterrâneas. Lisboa: Fundação Calouste Gulbenkian.

. "Rites as Acts of Institution". 1992. In J. G. Peristiany \& J. Pitt-Rivers (eds.) Honor and Grace in Anthropology. Cambridge: Cambridge University Press.

CAMPBELL, J. 1971 [1965]. "A Honra e o Diabo". In J.G. Peristiany (org.). Honra e Vergonha: valores das sociedades mediterrâneas. Lisboa: Fundação Calouste Gulbenkian.

CAMPBELL, J. K. 1992. “The Greek Hero". In J. G. Peristiany \& J. Pitt-Rivers (eds.) Honor and Grace in Anthropology. Cambridge: Cambridge University Press.

CAUFIELD, S. 2000. Em Defesa da Honra: moralidade e nação no Rio de Janeiro (1918-1940). Campinas: Ed. Unicamp. CORRÊA, Mariza. 1981. Os Crimes da Paixão. São Paulo: Brasiliense.

CUTILEIRO, José. 1971. "Prefácio à Edição Portuguesa: honra, vergonha e amigos". In J.G. Peristiany (org.). Honra e Vergonha: valores das sociedades mediterrâneas. Lisboa: Fundação Calouste Gulbenkian.

DAVIS, John. 1977. People of Mediterranean: an essay in comparative social anthropology. London: Routledge \& Kegan Paul.

DI BELLA, Maria Pia. 1992. “Name, Blood, and Miracles: the claims to renown in traditional Sicily”. In J. G. Peristiany \& J. Pitt-Rivers (eds.) Honor and Grace in Anthropology. Cambridge: Cambridge University Press.

DÓRIA, Carlos Alberto. 1994. "A Tradição Honrada". Pagu no 2: 47-111. Campinas: Unicamp/ Núcleo de Estudos de Gênero.

DUARTE, Luiz Fernando Dias. 1987. “Muita Vergonha, Pouca Vergonha: sexo e moralidade entre classes trabalhadoras urbanas". In José Sérgio Leite Lopes (org.) Cultura e Identidade Operária: aspectos da cultura da classe trabalhadora. Rio de Janeiro: UFRJ/PROED. 
FONSECA, Claudia. 2000. Família, Fofoca e Honra: etnografia de relações de gênero e violência em grupos populares. Porto Alegre: Ed. UFRGS.

HERZFELD, Michael. 1980. "Honour and Shame: problems in the comparative analysis of moral systems". Man 5(2): 339-351.

. 1984. "The Horns of the Mediterraneanist Dilemma". American Ethnologist 11(3): 439-454.

JAMOUS, Raymond. 1991. “De quoi Parlent les Fusils?" In M. Gautheron (org.) L'Honneur. Image de soi ou don de soi: un idéal équivoque. Paris: Autrement. Série Morales no3.

. 1992. "From the Death of Men to the Peace of God: violence and peace-making in the Rif. In J. G. Peristiany \& J. Pitt-Rivers (eds.) Honor and Grace in Anthropology. Cambridge: Cambridge University Press.

LADURIE, Emmanuel L. 1992. "The Court Surrounds the King: Louis XIV, the Palatine Princess, and Saint Simon”. In J. G. Peristiany \& J. Pitt-Rivers (eds.) Honor and Grace in Anthropology. Cambridge: Cambridge University Press.

LAFAGES, Catherine. 1992. "Royality and Ritual in the Middle Ages: coronation and funerary rites in France". In J. G. Peristiany \& J. Pitt-Rivers (eds.) Honor and Grace in Anthropology. Cambridge: Cambridge University Press.

LEFÈBVRE, Bruno. 1991. “L'Argent et le Secret: dégradations et recompositions”. In M. Gautheron (org.) L'Honneur. Image de soi ou don de soi: un idéal équivoque. Paris: Autrement. Série Morales no3.

LÉVY, Marie-Françoise, Anne Muxel \& Annick Percheron. 1991. “Tableaux d'Honneur”. In M. Gautheron (org.) L'Honneur. Image de soi ou don de soi: un idéal équivoque. Paris: Autrement. Série Morales no3.

MUCHEMBLED, Robert. 1991. "Les Humbles Aussi”. In M. Gautheron (org.) L'Honneur. Image de soi ou don de soi: un idéal équivoque. Paris: Autrement. Série Morales no3.

OTT, Sandra. 1992. "Indarra: some reflections on a basque concept". In J. G. Peristiany \& J. Pitt-Rivers (eds.) Honor and Grace in Anthropology. Cambridge: Cambridge University Press.

PERISTIANY, J. G. (org.). 1971 [1965]. Honra e Vergonha: valores das sociedades mediterrâneas. Lisboa: Fundação Calouste Gulbenkian. Gulbenkian.

1971 [1965]. “Introdução”. In Honra e Vergonha: valores das sociedades mediterrâneas. Lisboa: Fundação Calouste

1971 [1965]. “Honra e Vergonha numa Aldeia Cipriota de Montanha”. In J. G. Peristiany (org.) Honra e Vergonha: valores das sociedades mediterrâneas. Lisboa: Fundação Calouste Gulbenkian.

. 1992. "The Sophron - a secular saint? Wisdom and the wise in a Cypriot community". In J.G. Peristiany \& J. PittRivers (eds.) Honor and Grace in Anthropology. Cambridge: Cambridge University Press.

PERISTIANY, J. G. \& J. Pitt-Rivers (eds.). 1992. Honor and Grace in Anthropology. Cambridge: Cambridge University Press.

. 1992. "Introduction". In J. G. Peristiany \& J. Pitt-Rivers (eds.) Honor and Grace in Anthropology. Cambridge:

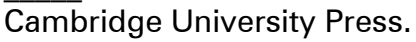

PERROT, Michelle. 1991. "Dramas e Conflitos Familiares”. In M. Perrot (org.) História da Vida Privada IV: Da Revolução Francesa à Primeira Guerra. São Paulo: Companhia das Letras.

PINA CABRAL, João de. 1991. "As Categorias de Comparação Regional: uma crítica à noção de Mediterrâneo". In Os 
PITT-RIVERS, Julian. 1971 [1965]. “Honra e Posição Social”. In J.G. Peristiany (org.). Honra e Vergonha: valores das sociedades mediterrâneas. Lisboa: Fundação Calouste Gulbenkian. . 1979. “La Antropología del Honor". In Antropología del Honor. Barcelona: Crítica.

1991. “La Maladie de I'Honneur". In M. Gautheron (org.) L'Honneur. Image de soi ou don de soi: un idéal équivoque. Paris: Autrement. Série Morales no3.

1992. "Postscript: the place of grace in anthropology". In J. G. Peristiany \& J. Pitt-Rivers (eds.) Honor and Grace in Anthropology. Cambridge: Cambridge University Press.

. 1977. "The Moral Foundations of the Family". In The Fate of Schechem. Cambridge: Cambridge University $\overline{\text { Press. }}$

ROHDEN, Fabíola. 1999. “Honra e Família em Algumas Visões Clássicas da Formação Nacional”. BIB- Revista Brasileira de Informação Bibliográfica em Ciências Sociais no 48: 69-89. Rio de Janeiro: ANPOCS/Relume Dumará.

SEED, Patricia. 1994. “Narrativas de Don Juan: a linguagem da sedução na literatura e na sociedade hispânica do século dezessete". Pagu no 2: 7-45. Campinas: Unicamp/ Núcleo de Estudos de Gênero.

VERNANT, Jean-Pierre. 1991. “La 'belle mort' de Achille". In M. Gautheron (org.) L'Honneur. Image de soi ou don de soi: un idéal équivoque. Paris: Autrement. Série Morales no3. 


\section{Para que Serve o Conceito de Honra, ainda hoje?}

\section{RESUMO}

Este ensaio bibliográfico traça um mapa do conceito de honra e seus afins, como as categorias vergonha e graça, em textos clássicos da antropologia que têm se dedicado à temática, procurando apontar para a diversidade de enfoques e traduções culturais em questão. Percorrendo a bibliografia sobre o conceito de honra é possível perceber que os estudos que têm tratado do tema giram em torno de um conjunto de referências comuns, centradas nas pesquisas que envolveram a chamada "área cultural mediterrânea" e suas críticas. É a partir das definições empregadas originalmente pelos autores que se dedicaram a mapear os sentidos do conceito de honra naquela região que as novas propostas se elaboram, trazendo dados etnográficos inéditos e aprimorando a discussão teórica. PALAVRAS-CHAVE: honra, vergonha, graça, teoria antropológica.

\section{What is the Use of the Concept of Honor, Today?}

\section{ABSTRACT}

This review article develops an inventory of the concept of honor and its affiliates (the categories shame and grace) throughout some classical anthropological works. It aims to indicate the diversity of approaches and the cultural translations implied in such concepts. The bibliographical analysis reveals that the anthropological studies about honor share a common ground. They have been developed around some theories, and its critics, related to the 'Mediterranean Cultural Area'. Based on definitions elaborated in relation to that cultural area, new approaches are being proposed incorporating original ethnographic data and improving the theoretical debate on the concept of honor. KEY WORDS: honor, shame, grace, anthropological theory. 